\title{
The risk of fatal car crashes in people with epilepsy
}

Karen C. Richards, MD

\section{What are seizures and epilepsy?}

Seizures are sudden, unpredictable events that can temporarily interfere with a person's ability to think or act normally. A person has epilepsy if he or she has had more than one seizure. Sometimes medication can control epilepsy, but not always. Seizures can cause injury or death if they happen while swimming or driving a car. More information about seizures and epilepsy appears on the next page.

\section{What does the law say about driving and seizures?}

Laws temporarily prohibit people from driving after a seizure. The restriction period varies by state (usually 3 to 12 months). If no seizures occur during the restriction period, the patient can drive again. However, sometimes seizures recur after long periods without seizures, even if a patient takes medicine to prevent seizures. Seizures more commonly recur if a patient stops taking seizure medications.

\section{What is the latest research on driving and epilepsy?}

In this issue of Neurology, researchers from Johns Hopkins University studied how often seizures or epilepsy cause fatal car accidents. ${ }^{1}$ They looked at death certificates of drivers who died in car crashes from 1995 to 1997.
About 44,027 US drivers die each year in car crashes. Only 86 of these death certificates $(0.2 \%)$ listed seizures or epilepsy as a contributing factor. Alcohol caused 156 times more driver deaths than seizures. Young drivers (age 16 to 24) died in accidents 123 times more often than drivers of any age who crashed due to a seizure. The driver fatality crash rate for the general population was 2.6 times higher than epilepsy-related driver fatalities. This is because seizures rarely cause crashes, but alcohol use, driver error, or road conditions often do.

The researchers also compared driver fatality crashes with other causes of death for epilepsy patients. The most common cause of death for epilepsy patients was heart disease, the same as in the general population. Epilepsy patients more often died of accidental drowning, suffocation, or brain tumors than people without epilepsy. Epilepsy is directly related to all three of these events or conditions.

\section{Driving restrictions for epilepsy patients}

Driving restriction for epilepsy patients causes a dilemma. It is very difficult to work or even run errands if a person cannot drive. However, states must consider both patient and public safety. In this study, the length of driving restric- tion after a seizure did not seem to matter. The seizure-related fatal crash rate of drivers in states with 6- to 12-month restrictions was the same as in states with 3-month restrictions. Other studies have shown that longer restriction periods are associated with lower crash rates. Future research may identify which epilepsy patients are at the lowest risk for seizures. This could lead to new rules that would shorten restrictions for these patients.

\section{What does this mean to me?}

Even though seizures rarely cause car accidents, they sometimes do. Also, this study counted only deaths of drivers, not passengers or pedestrians. Accidents causing non-fatal injuries were also not counted. If you have epilepsy, you can lower your chances of having seizures while driving. Always take your seizure medicine as directed by your doctor. Never stop your medicine suddenly. Never drive when overly tired or if you have a fever. These things can trigger seizures in people even if they are taking medicine. Of course, it is never a good idea for anyone to drink alcohol and drive.

\section{Reference}

1. Sheth SG, Krauss G, Krumholz A, Li G. Mortality in epilepsy: driving fatalities vs other causes of death in patients with epilepsy. Neurology 2004;63:1002-1007. 


\section{What is a seizure?}

A seizure is a disruption in the normal electrical activity of the brain. Normally the brain is very active, passing electrical messages back and forth between nerve cells. When a person has a seizure, there is abnormal firing of nerve cells and the messages become jumbled in part or all of the brain.

A seizure may cause a variety of different symptoms, such as twitching or shaking in an arm, leg, one side of the face, or the whole body; repetitive movements or gestures; confusion; feelings of fear or other emotions; hallucinations (odd smells, tastes, sounds, or seeing things that are not there); loss of consciousness; and convulsions.

\section{What causes seizures?}

Anyone may have a seizure in certain conditions. Common causes are fever (in young children) (see febrile seizures, below); head trauma (during birth or any time later); infection of the brain or nervous system (e.g., meningitis); brain tumors; very low blood sugar; stroke (a brain attack); lack of oxygen to the brain; and poisoning (e.g., alcohol and various drugs).

\section{What are febrile seizures?}

Febrile seizures are generally benign and occur in children from ages 3 months to 5 years, with average age at onset of 18 to 22 months. They occur in the setting of a febrile illness, usually as the fever is rising fast. They are associated with common childhood infections such as ear infections, tonsillitis, upper airway infections, and gastrointestinal infections. Most are associated with viral illnesses.

Febrile seizures are more common in boys. They also tend to run in families. About one third of children who have a first febrile seizure will have a second one, almost always within 2 years. The earlier the onset of febrile seizures, the greater chance that they will recur. However, less than $5 \%$ of children with febrile seizures go on to develop epilepsy.

Although febrile seizures are usually benign, it is critical that the child be evaluated immediately to identify the cause of the fever and treat conditions such as meningitis or intoxication.

\section{What is epilepsy?}

Epilepsy is an episodic recurrence of seizures that are not due to fever, active infection, drug effects, or other triggering causes. It may be caused by a variety of conditions that injure a part or all of the brain, such as problems in development of the brain that occurs before birth, inherited disorders of the brain or nervous system, brain trauma, brain tumors, stroke, infections, and poisoning. About $70 \%$ of cases have no known cause.

Each year there are 125,000 new cases of epilepsy. About 2.5 million people in the United States have some form of epilepsy.

\section{How is epilepsy diagnosed?}

The doctor will need to know as much as possible about what happened during, immediately before, and after the seizure. How often seizures occur, whether there are any warning signs, and whether the patient remembers anything about the seizure are all important. Someone who has witnessed the seizures can provide valuable information that the patient may not know.
Electroencephalography (EEG) is a simple and painless study that records the brain's electrical activity picked up by tiny wires taped to the head. Specific brain wave patterns may be noted during or between seizures in patients with epilepsy and may help with diagnosis.

Imaging studies to look at the brain may be helpful in locating tumors, scars, or other abnormalities that may be causing seizures. MRI (magnetic resonance imaging) and CT (computed tomography) scans create pictures of the inside of the brain.

\section{How is epilepsy treated?}

Drugs called anticonvulsants are used most commonly to treat seizures. There are a number of different medications that can be used, alone or in combination. These drugs are effective in 60 to $80 \%$ of cases. Close supervision by a doctor is essential to watch for side effects and obtain the best seizure control.

People with epilepsy can help control seizures by avoiding alcohol and caffeine, avoiding unusual stress, getting enough sleep, taking their medications as prescribed, and working closely with their doctor. A special diet may be helpful in controlling certain types of seizures in children but requires very close medical supervision. Surgery may be very helpful when medication fails and the area of the brain where the seizure occurs is known.

\section{For more information}

AAN Foundation:

www.thebrainmatters.org

Epilepsy Foundation of America: www.efa.org 


\title{
Neurology
}

\author{
The risk of fatal car crashes in people with epilepsy \\ Karen C. Richards \\ Neurology 2004;63;E12 \\ DOI 10.1212/01.WNL.0000142227.69091.D0
}

This information is current as of September 27, 2004

\section{Updated Information \&} Services

References

Permissions \& Licensing

Reprints including high resolution figures, can be found at: http://n.neurology.org/content/63/6/E12.full

This article cites 1 articles, 1 of which you can access for free at: http://n.neurology.org/content/63/6/E12.full\#ref-list-1

Information about reproducing this article in parts (figures,tables) or in its entirety can be found online at:

http://www.neurology.org/about/about_the_journal\#permissions

Information about ordering reprints can be found online: http://n.neurology.org/subscribers/advertise

Neurology ${ }^{\circledR}$ is the official journal of the American Academy of Neurology. Published continuously since 1951, it is now a weekly with 48 issues per year. Copyright. All rights reserved. Print ISSN: 0028-3878. Online ISSN: 1526-632X.

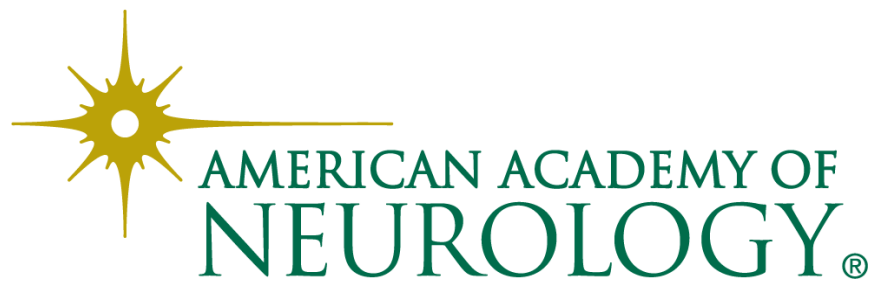

